ХИМИЯ

УДК 154.65

О. Ю. Курапова, В. Г. Конаков, С. Н. Голубев, В. М. Уиаков

ФАЗООБРАЗОВАНИЕ И СТАБИЛЬНОСТЬ ТВЁРДЫХ РАСТВОРОВ
В НАНОРАЗМЕРНЫХ ПРЕКУРСОРАХ НА ОСНОВЕ ДИОКСИДА
ЦИРКОНИЯ, ПОЛУЧЕННЫХ КРИОХИМИЧЕСКИМИ МЕТОДАМИ*

Санкт-Петербургский государственный университет,

Российская Федерация, 199034, Санкт-Петербург, Университетская наб., 7-9

Исследована взаимосвязь между последовательностью превращений «аморфная фаза $\rightarrow$ метастабильный кристаллический твёрдый раствор $\rightarrow$ стабильный кристаллический твёрдый раствор» в наноразмерных прекурсорах итоговых составов $\mathrm{ZrO}_{2}, 5 \mathrm{CaO}-95 \mathrm{ZrO}_{2}$ и $9 \mathrm{CaO}-91 \mathrm{ZrO}_{2}$, полученных криохимическими методами. Было установлено, что кинетическая стабилизация метастабильных фаз в требуемом температурно-концентрационном интервале может быть достигнута за счёт корректного выбора метода обработки гелей, полученных золь-гель синтезом. Применение криохимической обработки позволяет элиминировать процессы агломерации прекурсоров в области температур до $1000^{\circ} \mathrm{C}$. Библиогр. 22 назв. Ил. 6. Табл. 4.

Ключевые слова: золь-гель синтез, криохимическая обработка, лиофильная сушка, метастабильный твёрдый раствор на основе стабилизированного диоксида циркония, правило ступеней Оствальда.

O. Yu. Kurapova, V. G. Konakov, S. N. Golubev, V. M. Ushakov

\title{
PHASE FORMATION AND STABILITY OF SOLID SOLUTIONS IN NANOSIZED ZIRCONIA BASED POWDERS, OBTAINED BY CRYOCHEMICAL ROUTE
}

St. Petersburg State University, 7-9, Universitetskaya nab., St. Petersburg, 199034, Russian Federation

The paper reports the correlations in the sequence "amorphous phase $\rightarrow$ metastable crystalline solid solution $\rightarrow$ stable crystalline solid solution" in nanosized $\mathrm{ZrO}_{2}, 5 \mathrm{CaO}-95 \mathrm{ZrO}_{2}$ and $9 \mathrm{CaO}$ $91 \mathrm{ZrO}_{2}$ precursors, obtained by reversed co-precipitation technique with following fast freezing in liquid nitrogen, freeze-drying and pan drying. It has been found that kinetic stabilization of metastable zirconia phases in the required region of temperatures and concentrations can be achieved via correct post-treatment of gels obtained by reversed co-precipitation technique. The use of cryochemical treatment allows to eliminate powders agglomeration up to $1000^{\circ} \mathrm{C}$. Refs 22 . Figs 6. Tables 4 .

Keywords: reversed co-precipitation technique, cryochemical treatment, freeze-drying, metastable stabilized zirconia solid solution, Ostwald step rule.

* Исследование выполнено при поддержке стипендии президента РФ для молодых учёных (НИР № СП-1967.2016.1)

(C) Санкт-Петербургский государственный университет, 2016 
Введение. Изучение последовательности превращений «аморфная фаза $\rightarrow$ метастабильный кристаллический твёрдый раствор $\rightarrow$ стабильный кристаллический твёрдый раствор» в наноразмерных системах представляет несомненный интерес для современной науки в области разработки новых материалов с регулируемыми физико-химическими характеристиками. Особое внимание привлекают наноразмерные прекурсоры на основе флюоритоподобных твёрдых растворов диоксида циркония, которые используются для изготовления наноструктурированной анионпроводящей керамики, сенсоров полноты сгорания топлива [1-3] и мембран для твердооксидных топливных элементов (ТОТЭ) [4], а также применяются в качестве добавки для улучшения свойств различных органических и неорганических материалов. Среди них стоит выделить композиты нового поколения, получаемые на основе металлических матриц типа $\mathrm{Ni}, \mathrm{Al}$ и $\mathrm{Cu}$, а также теплоизоляционные плиты на основе пенополиуретана (ППУ) для транспортировки сжиженного газа и сферопластиков специального назначения.

Известно, что свойства разрабатываемых материалов (как, например, высокие значения анионной проводимости, повышенная прочность, термостойкость, пористость и т. д.) во многом зависят от дисперсности и итогового фазового состава наноразмерных порошков, которые выступают в качестве прекурсоров или модификаторов [5-7]. При этом необходима стабилизация именно флюоритоподобного $\mathrm{ZrO}_{2}$, поскольку использование низкосимметричных модификаций (моноклинной и тетрагональной форм) не позволяет получить материалы с требуемыми характеристиками. Введение в $\mathrm{ZrO}_{2}$ легирующих добавок (оксиды щелочноземельных металлов, редкоземельные элементы) приводит к образованию флюоритоподобных твёрдых растворов и появлению в их кристаллических решётках большого количества анионных вакансий. С позиций равновесных фазовых диаграмм область существования флюоритоподобных твёрдых растворов на основе $\mathrm{ZrO}_{2}$ зависит от температуры, типа и количества введённого катиона-допанта, что подробно изложено в обзорах $[3,8,9]$. Необходимо отметить, что введение катионадобавки должно быть минимальным, чтобы избежать образования кластеров анионных вакансий и снижения проводимости итоговых материалов.

В недавних работах $[7,10]$ отмечается, что использование жидкофазных методов, таких как золь-гель синтез с последующей криохимической обработкой геля, позволяет получить и стабилизировать высокосимметричные модификации диоксида циркония в области температур ниже данных равновесных фазовых диаграмм систем на основе диоксида циркония за счёт сохранения высокой дисперсности прекурсоров на всех стадиях синтеза и дальнейшей обработки. Показано $[7,11]$, что использование лиофильной сушки способствует недеструктивному удалению дисперсионной среды (воды) за счёт её сублимации из твёрдой фазы в газ, что сводит к минимуму количество контактов между частицами дисперсной фазы. Последнее позволяет избежать образования прочных, не поддающихся разбиению агломератов. Термообработка полученных аморфных прекурсоров влечёт значительный сдвиг фазовых соотношений в системе, а также существенно влияет на механизм и кинетику фазообразования [10].

В связи с вышесказанным целью настоящей работы явилось установление взаимосвязи между последовательностью превращений «аморфная фаза $\rightarrow$ метастабильный кристаллический твёрдый раствор $\rightarrow$ стабильный кристаллический твёрдый раствор» и эволюцией размеров агломератов и кристаллитов в прекурсорах, полученных зольгель синтезом с последующей обработкой, при их термоэволюции в области $400-1300^{\circ} \mathrm{C}$ на примере модельных составов $\mathrm{ZrO}_{2}, 5 \mathrm{CaO}-95 \mathrm{ZrO}_{2}$ и $9 \mathrm{CaO}-91 \mathrm{ZrO}_{2}$ (здесь и далее по тексту составы указаны в мольных процентах). 
Экспериментальная часть. Для получения прекурсоров на основе чистого, частично стабилизированного и стабилизированного диоксида циркония использовали золь-гель синтез в варианте обратного соосаждения из раствора солей с различной последующей обработкой. Составы, отвечающие содержанию 5 и 9 мол. \% оксида кальция, были выбраны в соответствии с фазовой диаграммой системы $\mathrm{CaO}-\mathrm{ZrO}_{2}$ [12]. Децимолярные водные растворы солей приготовлены из стехиометрической смеси кристаллогидратов $\mathrm{ZrO}\left(\mathrm{NO}_{3}\right)_{2} \cdot n \mathrm{H}_{2} \mathrm{O}$ (ч. д. а.) и $\mathrm{Ca}\left(\mathrm{NO}_{3}\right)_{2} \cdot 2 \mathrm{H}_{2} \mathrm{O}$ (х. ч.). При расчёте массы навески учитывали точное содержание $\mathrm{ZrO}_{2}$ в итоговом прекурсоре. При этом количество кристаллизационной воды в кристаллогидрате нитрата цирконила определяли методом термогравиметрии. Осаждение аморфных гидроксидов проводили из раствора исходных кристаллогидратов, а в качестве осадителя использовали одномолярный водный раствор гидроксида аммония (х. ч.). Растворы солей добавляли со скоростью 1-2 мл/мин в охлаждённый до $1-2^{\circ} \mathrm{C}$ (с помощью ледяной бани) раствор осадителя при непрерывном перемешивании с помощью многолопастной мешалки. Значение рН среды поддерживали на уровне 9-10 единиц, добавляя раствор аммиака в процессе синтеза. Образовавшийся осадок фильтровали на воронке Бюхнера через фильтр со средним размером пор 250 нм и промывали до нейтральной реакции фильтрата. Полученный гель разделили на четыре части и подвергли последующей обработке (лиофильная сушка, лиофильная сушка с добавкой криопротектора в виде 10 вес. \% глицерина, криохимическая обработка жидким азотом, высокотемпературная сушка под избыточным давлением).

Лиофильная сушка. В [13] на примере итогового состава $9 \mathrm{CaO}-91 \mathrm{ZrO}_{2}$ с использованием методов CTA и PSD-анализа были подобраны оптимальные условия лиофильной сушки гелей, приводящие к получению низкоагломерированных порошков. Для этого тонкий слой осадка наносили на поверхность чашки Петри. Затем чашки с образцами замораживали под коллектором лабораторного лиофилизатора Labconco, 11 chamber, USA (при температуре $-50^{\circ} \mathrm{C}$ и скорости охлаждения $\approx 1 \div 2{ }^{\circ} \mathrm{C} /$ мин). Замороженный образец быстро переносили в сублимационную камеру для последующей лиофильной сушки (0,018 торр, $20^{\circ} \mathrm{C}, 24$ ч).

Лиофильная сушка с добавкой криопротектора. Для того чтобы уменьшить растрескивание геля при замерзании, к отмытому гелю добавляли криопротектор - глицерин. Тип и количество криопротектора были выбраны на основании предварительных исследований, проведённых авторами [14]. Образцы гелей итоговых составов $\mathrm{ZrO}_{2}, 5 \mathrm{CaO}-95 \mathrm{ZrO}_{2}, 9 \mathrm{CaO}-91 \mathrm{ZrO}_{2}$ с содержанием глицерина 10 вес. \%, приготовленные весовым способом, подвергали лиофильной сушке по способу, описанному выше.

Криохимическая обработка жидким азотом. Криохимическая обработка представляла собой мгновенную заморозку небольших частей геля каждого из указанных итоговых составов в жидком азоте $\left(T_{k}=-195^{\circ} \mathrm{C}\right)$. Свежеприготовленный осадок небольшими порциями помещали в сосуд Дьюара, наполненный жидким азотом и снабжённый механической мешалкой. Перемешивание необходимо для дробления образующейся «корки» замороженного геля, препятствующей контакту жидкого азота со следующими порциями и, таким образом, равномерной заморозке. После испарения жидкого азота замороженный гранулят выкладывали тонким слоем на бумагу и сушили на воздухе.

Высокотемпературная сушка под избыточным давлением. Сушку проводили по методике, описанной в [15]. Для этого небольшое количество свежеприготовленных гелей итоговых составов $\mathrm{ZrO}_{2}, 5 \mathrm{CaO}-95 \mathrm{ZrO}_{2}, 9 \mathrm{CaO}-91 \mathrm{ZrO}_{2}$ массой 0,25-0,5 г растирали между двумя гладкими химически инертными пластинами (например, двумя 
чашечками Петри), после чего их прижимали грузом с силой порядка 1 кг/ см² и помещали в сушильный шкаф с температурой около $120^{\circ} \mathrm{C}$ до высыхания ( $~ 13 \div 15$ мин). Затем слой полученного порошка снимали, цикл при надобности повторяли вновь. Все образцы, полученные с применением последующей обработки, пронумерованы и представлены в табл. 1. По результатам данных СТА прекурсоры, полученные криохимическими методами (лиофильная сушка с добавкой криопротекторов и без них, криохимическая обработка жидким азотом), параллельно прокалили при 400, 600, 800, 1000 и $1300^{\circ} \mathrm{C}$.

Таблииа 1

\section{Итоговые составы прекурсоров, полученных криохимическими методами обработки осадка аморфных гидроксидов}

\begin{tabular}{|c|c|c|}
\hline $\begin{array}{c}\text { Номер } \\
\text { образца }\end{array}$ & $\begin{array}{c}\text { Итоговый } \\
\text { состав прекурсора }\end{array}$ & Вид последующей обработки \\
\hline I.1 & \multirow{2}{*}{$\mathrm{ZrO}_{2}$} & Лиофильная сушка \\
\hline$\overline{\mathrm{I} .4}$ & & Высокотемпературная сушка под избыточным давлением \\
\hline II.1 & \multirow{4}{*}{$5 \mathrm{CaO}-95 \mathrm{ZrO}_{2}$} & Лиофильная сушка \\
\hline II.2 & & Криохимическая обработка жидким азотом \\
\hline II.3 & & Лиофильная сушка с 10 вес. \% глицерина \\
\hline II.4 & & Высокотемпературная сушка под избыточным давлением \\
\hline III.1 & \multirow{4}{*}{$9 \mathrm{CaO}-91 \mathrm{ZrO}_{2}$} & Лиофильная сушка \\
\hline III.2 & & Криохимическая обработка жидким азотом \\
\hline III.3 & & Лиофильная сушка с 10 вес. \% глицерина \\
\hline III.4 & & Высокотемпературная сушка под избыточным давлением \\
\hline
\end{tabular}

Методы исследования. Для установления типа и температур фазовых превращений все наноразмерные прекурсоры после синтеза были исследованы методом синхронного термического анализа (СТА), включающего дифференциальный термический анализ (ДСК) и термогравиметрию (ТГ), на синхронном термоанализаторе STA 449 F1 Jupiter Netzsch в потоке азота при скорости нагрева 10 град./мин.

Рентгенофазовый анализ (РФА) наноразмерных прекурсоров после термообработки при 400-1300 ${ }^{\circ} \mathrm{C}$ проводили на дифрактометре XRD-6000 SHIMADZU с использованием $\mathrm{Cu}-\mathrm{K}_{\alpha}$-излучения $(\lambda=1,54 \AA)$ при комнатной температуре. Для идентификации веществ и сингоний использовали картотеку PDF-2. Средний размер кристаллитов (т. е. размер областей когерентного рассеяния) оценивали по профилю наиболее интенсивного рефлекса с использованием формулы Шерера

$$
d_{x r d}=k \frac{57,3 \lambda}{\Delta \cos \Theta}
$$

где $d_{x r d}-$ размер области когерентного рассеяния (размер кристаллитов); $\Theta-$ угол дифракции; $k$ - постоянная Шерера, зависящая от формы кристаллита, принята и рекомендуется равной $1 ; \lambda$ - длина волны падающего излучения $(\lambda=1,54 \AA) ; \Delta$ - ширина рефлекса на его полувысоте, в градусах. Средний размер агломератов в наноразмерных прекурсорах измеряли методом PSD-анализа (англ. Particle Size Distribution analysis) на лазерном анализаторе Horiba partica LA-950.

Экспериментальные результаты и их обсуждение. Как уже упоминалось, сохранение высокой дисперсности гелей, достигнутой на стадии золь-гель синтеза, и, таким образом, возможность сдвига температур фазовых переходов в низкотемпературную область и расширения области существования метастабильных твёрдых растворов 


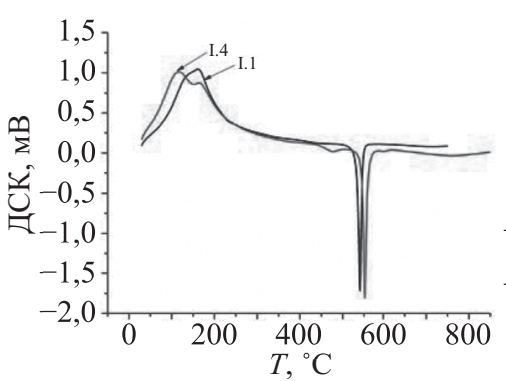

6

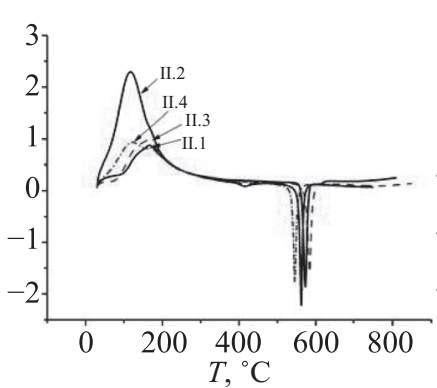

B

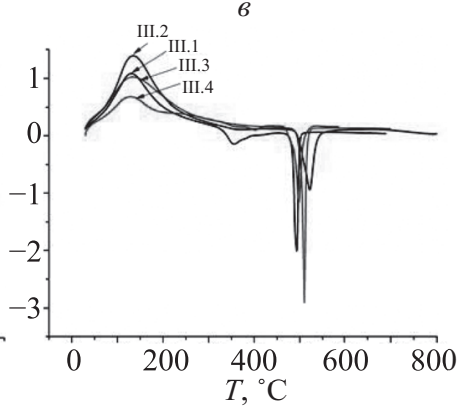

Puc. 1. Данные ДСК для прекурсоров итоговых составов: $a-\mathrm{I}, \sigma-\mathrm{II}, \boldsymbol{\varepsilon}-\mathrm{III}$

на основе стабилизированного диоксида циркония предопределяется выбранной методикой последующей обработки гелей. На рис. 1 приведены термограммы прекурсоров составов I-III, полученых криохимической обработкой гелей, а также высокотемпературной сушкой под избыточным давлением.

На представленных термограммах видно, что на кривых ДСК каждого из образцов можно выделить три основные области: эндотермический эффект при $\approx 100 \div 150^{\circ} \mathrm{C}$, отвечающий дегидратации и два экзотермических эффекта при $\approx 360^{\circ} \mathrm{C}$ и в области 490-550 ${ }^{\circ}$, соответствующих кристаллизации с образованием флюоритоподобного твёрдого раствора на основе $\mathrm{ZrO}_{2}$. Широкие эндотермические пики в области $T \leqslant 400^{\circ} \mathrm{C}$ свидетельствуют о постепенном процессе дегидратации. Поскольку образование СаO из $\mathrm{Ca}(\mathrm{OH})_{2}$ происходит только при $\approx 550^{\circ} \mathrm{C}[16]$, а удаление воды из $\mathrm{Zr}(\mathrm{OH})_{4}$ за счёт перехода гель $\rightarrow$ золь начинается уже при $\approx 140^{\circ} \mathrm{C}$ [17], логично предположить, что суммарные потери воды при температурах $\leqslant 400^{\circ} \mathrm{C}$ происходят в основном за счёт дегидратации $\mathrm{Zr}(\mathrm{OH})_{4}$. Для всех исследованных образцов процесс удаления воды заканчивается только при $\approx 1100^{\circ} \mathrm{C}$, что характерно для циркониевых прекурсоров в целом [18]. Примечательно, что добавление глицерина при лиофильной сушке состава III способствует сдвигу эндотермического эффекта, отвечающего дегидратации, в высокотемпературную область. Температура для этого пика $\left(\approx 140 \div 145^{\circ} \mathrm{C}\right)$ соответствует началу потери структурно-связанной воды [16]. Необходимо отметить, что по данным ИК-фурье-спектроскопии количество остаточного глицерина в порошках после лиофильной сушки не превышает 0,84 г/моль. Таким образом, для прекурсоров, полученных лиофильной сушкой с добавкой глицерина, потери массы в области $\leqslant 400^{\circ} \mathrm{C}$ можно полностью отнести к потерям воды.

В случае наноразмерных прекурсоров итоговых составов I и II, полученных высокотемпературной сушкой под избыточным давлением, потери дисперсионной и структурно-связанной воды происходят последовательно согласно реакциям:

$$
\begin{gathered}
\mathrm{Zr}(\mathrm{OH})_{4} \rightarrow \mathrm{ZrO}(\mathrm{OH})_{2}+\mathrm{H}_{2} \mathrm{O} \\
\mathrm{ZrO}(\mathrm{OH})_{2} \rightarrow \mathrm{ZrO}_{2}+\mathrm{H}_{2} \mathrm{O}
\end{gathered}
$$

Напротив, для прекурсоров, полученных криохимическими методами, формирование безводного $\mathrm{ZrO}_{2}$ связано с непрерывным изменением состава конденсированной фазы. Общие потери массы исследованными образцами в области $\leqslant 400^{\circ} \mathrm{C}$ в расчёте на 1 моль итогового состава для кривых ТГ и - для сравнения - теоретические потери структурно-связанной воды в этой области приведены в табл. 2. Расчёт проводили из предположения, что вся вода в прекурсорах содержится в виде смеси гидроксидов, от- 
вечающих общей формуле $x \mathrm{Ca}(\mathrm{OH})_{2}(100-x) \operatorname{Zr}(\mathrm{OH})_{4}$, где $x=0,5$ и 9 . Наличие двух разрешённых пиков на кривых ДСК некоторых прекурсоров дало возможность оценить потери дисперсионной и структурно-связанной воды. Точность измерения потерь массы образцами на приборе типа Netzsch STA 449 F3 Jupiter составляет 0,1 мг.

\section{Потери массы прекурсорами итоговых составов I-III по данным CTA}

\begin{tabular}{|c|c|c|c|c|}
\hline $\begin{array}{c}\text { Номер } \\
\text { образца }\end{array}$ & $\begin{array}{c}\text { Потери воды } \\
\text { в области } 20-140^{\circ} \mathrm{C}, \\
\text { г/моль соед. }\end{array}$ & $\begin{array}{c}\text { Потери воды } \\
\text { в области } 140-400^{\circ} \mathrm{C}, \\
\text { г/моль соед. }\end{array}$ & $\begin{array}{c}\text { Потери воды } \\
\text { в области } \leqslant 400^{\circ} \mathrm{C}, \\
\text { г/моль соед. }\end{array}$ & $\begin{array}{c}\text { Теоретические } \\
\text { потери воды } \\
\text { в области } \leqslant 400^{\circ} \mathrm{C}, \\
\text { г/моль соед. }\end{array}$ \\
\hline I.1 & 13,5 & 15,87 & 29,38 & \multirow{2}{*}{27,84} \\
\hline I.4 & 9,65 & 22,5 & 31,4 & \\
\hline II.1 & 4,51 & 19,06 & 23,57 & \multirow{4}{*}{27,28} \\
\hline II.2 & - & - & 59,57 & \\
\hline II.3 & 7,06 & 20,1 & 27,16 & \\
\hline II.4 & 10,77 & 18,1 & 28,79 & \\
\hline III.1 & - & - & 29,86 & \multirow{4}{*}{26,82} \\
\hline III.2 & - & - & 40,35 & \\
\hline III.3 & - & - & 29,86 & \\
\hline III.4 & - & - & 20,23 & \\
\hline
\end{tabular}

Судя по приведённым данным, можно сделать заключение: что применение высокотемпературной сушки под избыточным давлением способствует более полному удалению структурно-связанной воды, чем криохимические методы, что неизбежно сопровождается конденсацией по реакции:

$$
\equiv \mathrm{Zr}(\mathrm{OH})+(\mathrm{HO}) \mathrm{Zr} \equiv \rightarrow \equiv \mathrm{Zr}-\mathrm{O}-\mathrm{Zr} \equiv+\mathrm{H}_{2} \mathrm{O} \text {. }
$$

В случае криохимической обработки удаление воды из гелей происходит недеструктивно, и это позволяет свести к минимуму образование кислородных мостиков вследствие конденсации. Наиболее наглядно влияние различных методов обработки на процесс дегидратации можно проследить на примере итогового состава I (чистый $\mathrm{ZrO}_{2}$ ). Так, потери воды образцами I.1 и I.4 (лиофильная сушка и высокотемпературная сушка под избыточным давлением) составляют 15,87 и 22,5 г/моль соответственно, а теоретические потери структурно-связанной воды равны 27,84 г. В общем же для прекурсоров после лиофильной сушки с глицерином и без за исключением образца II.1, потери воды составляют $\approx 30$ г/моль соед. (25 вес. \%), а после криохимической обработки в жидком азоте они лежат в пределах $\approx 40 \div 55$ г/моль (см. таблицу) и превышают теоретическое значение. Это свидетельствует о том, что криохимическая обработка затрагивает внутреннюю структуру прекурсора в меньшей степени, чем высокотемпературная сушка под избыточным давлением. Согласно [18] сохранение структурно-связанной воды в наноразмерных прекурсорах вплоть до высоких температур обработки может выступать дополнительным фактором стабилизации метастабильных твёрдых растворов на основе диоксида циркония.

Температура формирования метастабильного флюоритоподобного твёрдого раствора, отвечающего усреднённой формуле $\mathrm{Ca}_{0,15} \mathrm{Zr}_{0,85} \mathrm{O}_{1,85}$, определяется количеством допанта и оказывается минимальной в случае добавки 9 мол. \% СаО. Однако для каждого из исследованных составов максимумы экзотермических эффектов, отвечающих 
кристаллизации, различаются незначительно. Такой узкий интервал температур кристаллизации $\left(20^{\circ} \mathrm{C}\right)$ говорит о близких размерах агломератов в полученных прекурсоpax, что подтверждается данными PSD-анализа. Для каждого из образцов была определена энтальпия кристаллизации. Результаты расчётов и температура кристаллизации представлены в табл. 3 .

Таблица 3

Энтальпия кристаллизации образцов, Дж/г, рассчитанная по данным ДСК, и температура кристаллизации прекурсоров, ${ }^{\circ} \mathrm{C}$

\begin{tabular}{|c|c|c|c|c|c|c|c|c|}
\hline \multirow[t]{2}{*}{ Состав } & \multicolumn{2}{|c|}{$\begin{array}{c}\text { Лиофильная } \\
\text { сушка }\end{array}$} & \multicolumn{2}{|c|}{$\begin{array}{c}\text { Криохимическая } \\
\text { обработка } \\
\text { в жидком азоте }\end{array}$} & \multicolumn{2}{|c|}{$\begin{array}{c}\text { Лиофильная сушка } \\
\text { с добавкой } 10 \text { вес. \% } \\
\text { глицерина }\end{array}$} & \multicolumn{2}{|c|}{$\begin{array}{c}\text { Высокотемпературная } \\
\text { сушка под избыточным } \\
\text { давлением }\end{array}$} \\
\hline & $\begin{array}{l}-\Delta H, \\
\text { Дж/г }\end{array}$ & $\begin{array}{l}\mathrm{T} \\
{ }^{\circ} \mathrm{C}\end{array}$ & $\begin{array}{l}-\Delta H, \\
\text { Дж/г }\end{array}$ & $\begin{array}{l}\mathrm{T} \\
{ }^{\circ} \mathrm{C}\end{array}$ & $\begin{array}{l}-\Delta H, \\
\text { Дж/г }\end{array}$ & $\begin{array}{l}\mathrm{T} \\
{ }^{\circ} \mathrm{C}\end{array}$ & $\begin{array}{c}-\Delta H, \\
\text { Дж/г }\end{array}$ & $\begin{array}{l}T \\
{ }^{\circ} \mathrm{C}\end{array}$ \\
\hline $\mathrm{I}$ & $104 \pm 10$ & 552 & - & - & - & - & $113 \pm 11$ & 541 \\
\hline II & $140 \pm 14$ & 562 & $146 \pm 14$ & 572,5 & $140 \pm 14$ & 583 & $127 \pm 13$ & 545 \\
\hline III & $162 \pm 16$ & 494 & $165 \pm 17$ & 493 & $160 \pm 16$ & 502 & $167 \pm 17$ & 500 \\
\hline
\end{tabular}

Согласно приведённым в таблице данным, величина энтальпийного эффекта $\Delta H$ для всех исследованных прекурсоров значительно изменяется в зависимости от коли-

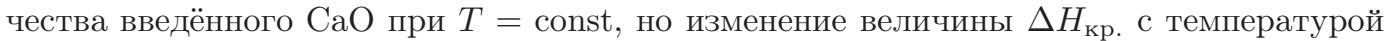
при фиксированном составе относительно мало. Значение энтальпии кристаллизации уменьшается по мере замещения $\mathrm{Zr}^{4+}$ ионами $\mathrm{Ca}^{2+}$ и в случае состава III $(9 \mathrm{CaO}-$ $\left.91 \mathrm{ZrO}_{2}\right)$ её среднее значение составляет -164 Дж/г. Сравнение полученных данных с литературными $[3,7,18]$ даёт возможность использовать величину энтальпии кристаллизации при фазовом переходе «аморфный прекурсор $\rightarrow$ кристаллический твёрдый раствор» в качестве критерия определения полноты кристаллизации метастабильных флюоритоподобных твёрдых растворов для системы $\mathrm{CaO}-\mathrm{ZrO}_{2}$.

Фазообразование в наноразмерных прекурсорах, полученных криохимической обработкой. В литературе имеется исчерпывающее количество публикаций, касающихся взаимосвязи дисперсности и фазообразования в прекурсорах, полученных методами высокотемпературной сушки под избыточным давлением, а также свойств керамики, полученной на их основе. Исследования были проведены ранее для большого числа высокодисперсных систем на основе диоксида циркония, как, например, $\mathrm{Y}_{2} \mathrm{O}_{3}-\mathrm{ZrO}_{2}, \mathrm{Al}_{2} \mathrm{O}_{3}-\mathrm{ZrO}_{2}, \mathrm{Ce}_{2} \mathrm{O}_{3}-\mathrm{ZrO}_{2}, \mathrm{Y}_{2} \mathrm{O}_{3}-\mathrm{ZrO}_{2}-\mathrm{Ce}_{2} \mathrm{O}_{3}$ [6, 19, 20]. В то же время такие данные для прекурсоров после лиофильной сушки и криохимической обработки жидким азотом отсутствуют. В связи с этим для последующей термообработки были выбраны составы, подвергнутые различной криохимической обработке.

Последовательное прокаливание прекурсоров итоговых составов I-III, обработанных с применением лиофильной сушки в различных вариантах и жидкого азота, в интервале $400-1300^{\circ} \mathrm{C}$ позволило проследить эволюцию фазового состава наноразмерных прекурсоров с термообработкой. Данные о фазообразовании представлены в табл. 4, где для удобства введены следующие сокращения: А - аморфный; М - моноклинный диоксид циркония (бадделеит); Т - тетрагональный твёрдый раствор на основе диоксида циркония; $\mathrm{K}$ - флюоритоподобный твёрдый раствор, отвечающий усреднённому составу $\mathrm{Ca}_{0,15} \mathrm{Zr}_{0,85} \mathrm{O}_{1,85}$; Нач. Kр. - начало кристаллизации прекурсора. 
Таблища 4

Фазовый состав прекурсоров в зависимости от метода обработки и температуры прокаливания, а также кристалличность образцов (указана в скобках)

\begin{tabular}{|c|c|c|c|c|c|}
\hline \multirow{2}{*}{ Состав } & \multicolumn{5}{|c|}{ при $T,{ }^{\circ} \mathrm{C}$} \\
\hline & 400 & 600 & 800 & 1000 & 1300 \\
\hline I.1 & $\mathrm{A}$ & $\mathrm{K}+\mathrm{M}(46)$ & $\mathrm{M}+\mathrm{K}(47)$ & $\mathrm{M}+\mathrm{K}(55)$ & $\mathrm{M}(60)$ \\
\hline II.1 & Нач. кр. & K + M (следы) (52) & $\mathrm{K}+\mathrm{M}+\mathrm{T}(57)$ & $\mathrm{K}+\mathrm{M}+\mathrm{T}(62)$ & $\begin{aligned} \mathrm{K} & : \mathrm{M}: \mathrm{T}= \\
& =50: 45: 5(57)\end{aligned}$ \\
\hline II. 2 & $\mathrm{~A}$ & K + M (следы) (52) & $\mathrm{K}+\mathrm{M}(64)$ & $\mathrm{K}+\mathrm{M}(73)$ & $\mathrm{K}: \mathrm{M}=45: 55(58)$ \\
\hline II.3 & Нач. кр. & K (52) & $\mathrm{K}+\mathrm{M}(55)$ & $\mathrm{K}+\mathrm{M}+\mathrm{T}(61)$ & $\begin{array}{l}\mathrm{K}: \mathrm{M}: \mathrm{T}= \\
\quad=55: 40: 5(58)\end{array}$ \\
\hline III.1 & K (49) & $\mathrm{K}(55)$ & $\mathrm{K}(61)$ & $\mathrm{K}+\mathrm{T}_{\text {искаж. }}(72)$ & $\mathrm{K}: \mathrm{M}=70: 30(63)$ \\
\hline III. 2 & Нач. кр. & K (54) & $\mathrm{K}(62)$ & $\mathrm{K}+\mathrm{T}_{\text {искаж. }}(72)$ & $\begin{array}{l}\mathrm{K}: \mathrm{M}: \mathrm{T}= \\
\quad=80: 10: 10(75)\end{array}$ \\
\hline III.3 & K (48) & $\mathrm{K}(56)$ & $\mathrm{K}(62)$ & $\mathrm{K}+\mathrm{T}_{\text {искаж. }}(74)$ & $\mathrm{K}: \mathrm{M}=70: 30(62)$ \\
\hline
\end{tabular}

По данным таблицы, количество введённого допанта, как и выбор метода последующей обработки гелей, влияет на кинетику фазообразования в наноразмерных прекурсорах. Применение лиофильной сушки в различных вариантах (с глицерином и без) способствует началу кристаллизации наноразмерных прекурсоров составов II и III уже при $400^{\circ} \mathrm{C}$, в то время как образцы, полученные обработкой исходного геля жидким азотом с последующей сушкой при атмосферных условиях, при этой температуре ещё рентгеноаморфны. Во всех случаях кристаллизация происходит в соответствии с эмпирическим правилом Оствальда и сопровождается образованием наиболее симметричной фазы - метастабильного флюоритоподобного твёрдого раствора на основе диоксида циркония. Интересно отметить, что даже в случае $\mathrm{ZrO}_{2}$ без стабилизирующих добавок (образец I.1), полученного криохимическими методами, кристаллизация аморфного прекурсора одновременно с формированием бадделеита также приводит к образованию значительного количества метастабильной кубической модификации. Сравнение полученного фазового состава прекурсора I.1 с данными равновесной фазовой диаграммы показывает, что появление стабильной модификации кубического диоксида циркония происходит только при $T \geqslant 2370^{\circ} \mathrm{C}$. Значит применение криохимических методов синтеза действительно способствует сдвигу фазовых соотношений в изучаемой системе.

Для прекурсоров итоговых составов II и III, полученных криохимической обработкой, стабилизация флюоритоподобного твёрдого раствора также наблюдается в области температур и составов, более широкой, чем на равновесной фазовой диаграмме $\mathrm{CaO}-\mathrm{ZrO}_{2}$ [12]. В обоих случаях твёрдый раствор отвечает усреднённой формуле $\mathrm{Ca}_{0,15} \mathrm{Zr}_{0,85} \mathrm{O}_{1,85}$. На рис. 2 представлены дифрактограммы прекурсоров итогового состава II, полученных с помощью лиофильной сушки и криохимической обработки в жидком азоте, с последующим прокаливанием при различных температурах. Как видно, добавки 5 мол. \% СаО недостаточно для стабилизации кубического твёрдого раствора и формирование флюоритоподобной фазы сопровождается появлением следовых количеств моноклинной фазы $(\approx 3 \div 6 \%)$. Дальнейшее увеличение температуры прокаливания до $800^{\circ} \mathrm{C}$ приводит к увеличению содержания моноклинного $\mathrm{ZrO}_{2}$, а в случае использования лиофильной сушки - к появлению дополнительных тетрагональных искажений. Конкурентный процесс фазообразования, по всей видимости, обусловливает наблюдаемые низкие значения кристалличности в прекурсорах I.1, II.1 и II.2 в области $600-1000^{\circ} \mathrm{C}$. Интересно отметить, что для состава II применение лиофильной сушки 

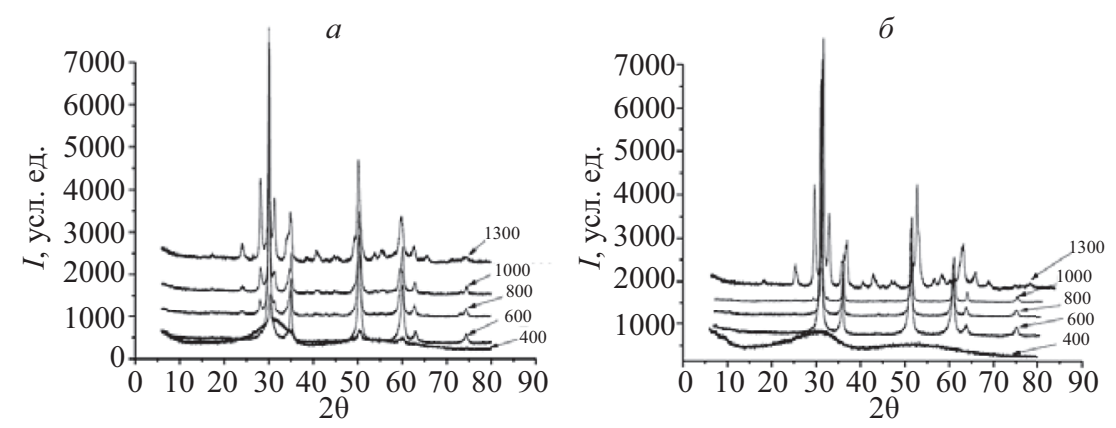

Puc. 2. Данные РФА прекурсоров II.1 (a) и II.2 (б) с добавкой 5 мол. \% СaО после прокаливания при $400,600,800,1000$ и $1300^{\circ} \mathrm{C}$ в течение 3 ч

при добавке 10 вес. \% глицерина способствует получению метастабильного кубического твёрдого раствора без примесей низкосимметричных фаз при $600^{\circ} \mathrm{C}$ и его стабилизации вплоть до $1000^{\circ} \mathrm{C}$; процесс сопровождается появлением незначительных количеств бадделеита (рис. 3).

Введение 9 мол. \% СаО в сочетании с недеструктивной криохимической обработкой даёт возможность добиться стабилизации кубического твёрдого раствора на основе диоксида циркония в области $400-1000^{\circ} \mathrm{C}$. Незначительное изменение кристалличности прекурсоров с повышением температуры позволяет сделать вывод о кинетической стабилизации флюоритоподобного твёрдого раствора в этой области.
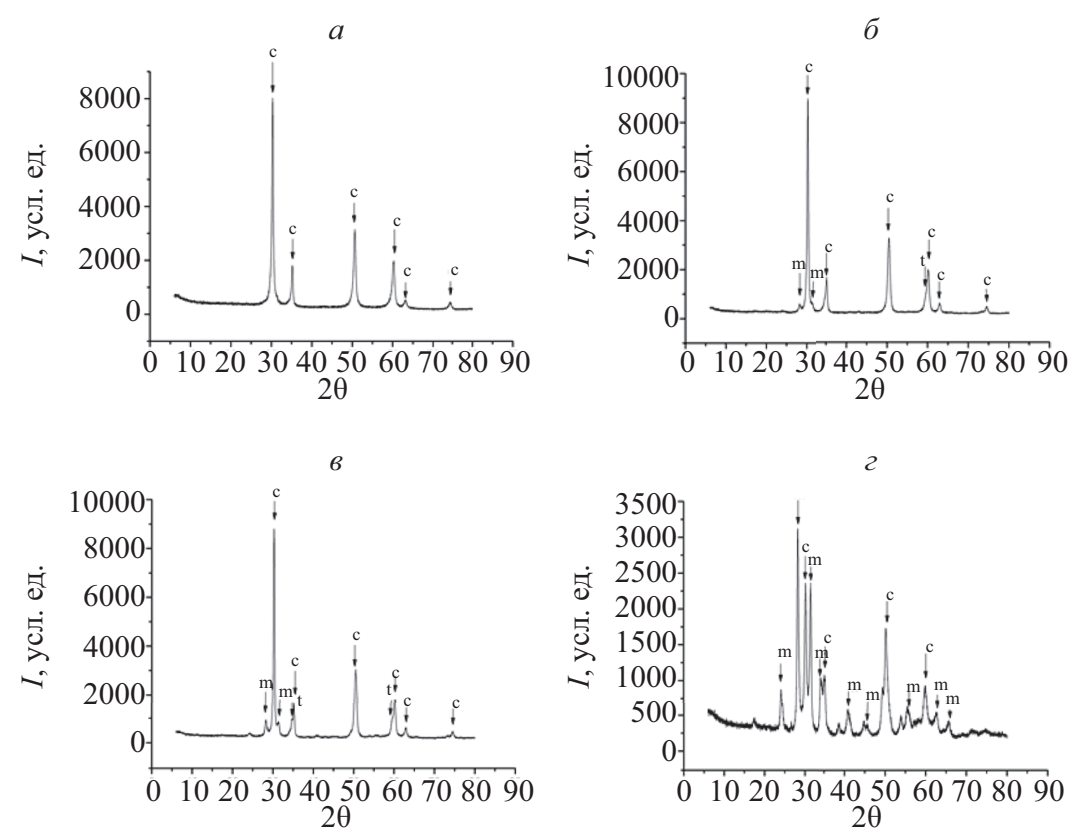

Puc. 3. Данные РФА прекурсора II.3 (лиофильная сушка геля итогового состава II с добавкой 10 вес. \% глицерина) после прокаливания при $600(a), 800(б), 1000\left(\right.$ в) и $1300^{\circ} \mathrm{C}($ ( ) в течение 3 ч:

c - кубический твёрдый раствор на основе $\mathrm{ZrO}_{2} ; \mathrm{m}-$ моноклинный $\mathrm{ZrO}_{2}$; $\mathrm{t}$ - тетрагональный твёрдый раствор на основе $\mathrm{ZrO}_{2}$ 
При $1300^{\circ} \mathrm{C}$ фазовые соотношения в наноразмерных прекурсорах всех исследованных составов стремятся к равновесным, о чём свидетельствует частичное разрушение кубического твёрдого раствора на основе $\mathrm{ZrO}_{2}$. При этом итоговый фазовый состав прекурсоров, прокаленных при этой температуре, определяется выбором методики обработки. Из представленных данных видно, что кинетическая стабилизация метастабильных фаз в требуемом температурно-концентрационном интервале может быть достигнута за счёт корректного выбора метода обработки гелей, полученных золь-гель синтезом. Наноразмерные порошки-прекурсоры с низкой степенью агломерации обладают избыточной поверхностной энергией, сопоставимой с энергией фазового перехода первого рода [1]. В связи с этим расширение области существования кубического твёрдого раствора на основе $\mathrm{ZrO}_{2}$ вплоть до $1100^{\circ} \mathrm{C}$ для всех исследованных составов может быть объяснено как малыми размерами кристаллитов (областей когерентного рассеяния ОКР), так и высокой дисперсностью полученных прекурсоров. Для всех исследуемых составов из данных РФА был оценён размер кристаллитов (OKP). Полученные данные представлены на рис. 4.

Puc. 4. Зависимость размера кристаллитов

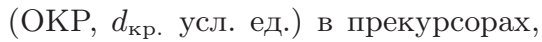
полученных криохимической обработкой, от температуры

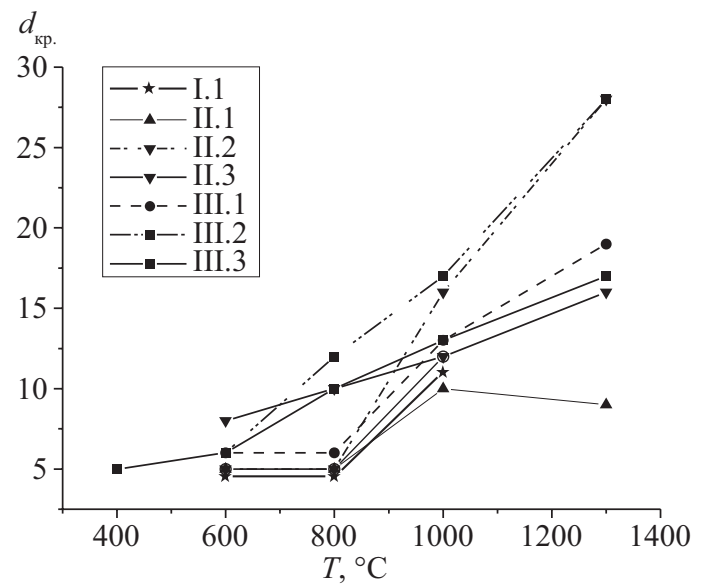

На рисунке видно, что прекурсоры, полученные в результате различной криохимической обработки гелей, являются наноразмерными, причём во всей области температур $400-1300^{\circ} \mathrm{C}$ процессы кристаллизации и рекристаллизации развиваются медленно, и оценённый размер кристаллитов в порошках не превышает 16-28 нм, что качественно согласуется с исследованиями [7]. На рисунке можно выделить два типа кривых, различающихся по скоростям роста кристаллитов кривых, относящихся к лиофильной сушке и криохимической обработке жидким азотом. Для всех исследованных составов после лиофильной сушки без добавок проявляется плато в области $600-800^{\circ} \mathrm{C}$. Наблюдаемое различие в кинетике роста ОКР, по-видимому, обусловлено различной стабильностью твёрдых растворов на основе диоксида циркония и разрушением кубической модификации при термообработке, что полностью подтверждается результатами РФА (см. табл. 4). В целом эти зависимости характеризуются квазилинейным характером роста ОКР, что может свидетельствовать о том, что размер кристаллитов вносит наибольший вклад в уширение дифракционной линии [21].

Изменение дисперсности в наноразмерных прекурсорах при их термообработке. Для составов II и III после криохимической обработки методом PSD-анализа были получены распределения по «числу частиц», т. е. доли частиц определённого 
диаметра относительно общего числа частиц в исследуемом образце. Характеристические распределения по «числу частиц» для прекурсора III.1 с термообработкой представлены на рис. 5 .

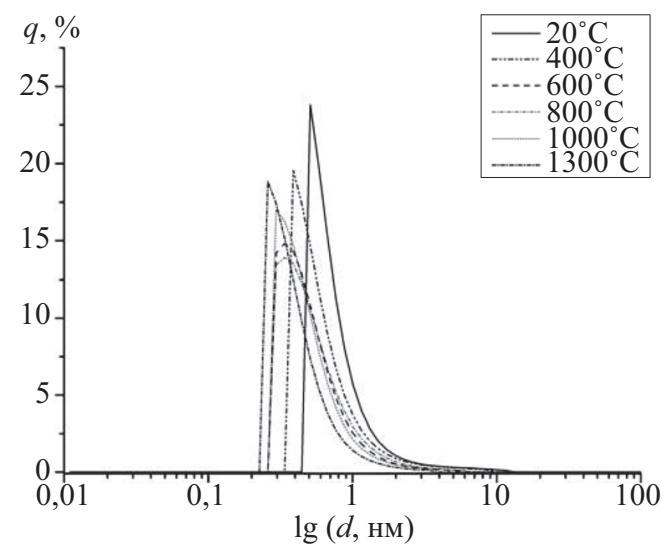

Puc. 5. Распределение частиц «по размеру» $(q)$ при различных температурах прокаливания для состава III.1

Можно убедиться, что все полученные распределения лежат в одной области и характеризуются узким распределением «по числу частиц». Примечательно, что увеличение температуры прокаливания до $1300^{\circ} \mathrm{C}$ не способствует общему изменению формы кривых и увеличению вклада крупных агломератов в распределение, как это наблюдается при термоэволюции агломератов в прекурсорах после высокотемпературной сушки под избыточным давлением [19, 20]. Для всех прекурсоров после криохимической обработки были получены близкие результаты, что свидетельствует о схожем механизме фазообразования. Стоит отметить, что понятия «агломерат» и «кристаллит» имеют разный физический смысл: «кристаллит» - это область когерентного рассеяния, размер которой оценивается из данных РФА, а «агломерат» - совокупность частиц дисперсной фазы, связанных между собой слабыми силами взаимодействия. Частицы дисперсной фазы, в свою очередь, имеют мозаичную структуру и составлены из кристаллитов, пространственно разделенных между собой аморфной фазой. При этом с ростом температуры прокаливания размер кристаллитов растёт, а доля аморфной фазы уменьшается и размер кристаллитов стремится к размеру самой частицы дисперсной фазы. Таким образом, данные размеров кристаллитов, полученные методом РФА, и данные размеров агломератов, полученные методом лазерной седиментографии, не эквивалентны. Их взаимосвязь можно проследить при сравнении кривых зависимости среднего размера агломератов в прекурсорах и кривых зависимости размера кристаллитов от температуры.

Для этого на основании кривых гранулометрического распределения был определён средний размер агломератов и построены кривые зависимости среднего размера агломератов в прекурсорах II и III от температуры. Полученные данные сравнили с зависимостями, представленными ранее в работе [22], после высокотемпературной сушки под избыточным давлением на примере состава $8 \mathrm{Y}_{2} \mathrm{O}_{3}-25 \mathrm{TiO}_{2}-\mathrm{ZrO}_{2}$ (рис. 6). На рисунке видно, что для рассмотренных составов криохимическая обработка в различных вариантах ведёт к получению в целом более высокодисперсных порошков, чем высокотемпературная сушка под избыточным давлением.

Рассмотрим процесс термоэволюции порошков в случае каждого из применяемых методов обработки более детально. В случае высокотемпературной сушки под избыточным давлением ниже температуры кристаллизации $\left(\approx 520^{\circ} \mathrm{C}\right.$ для состава $8 \mathrm{Y}_{2} \mathrm{O}_{3}-$ 

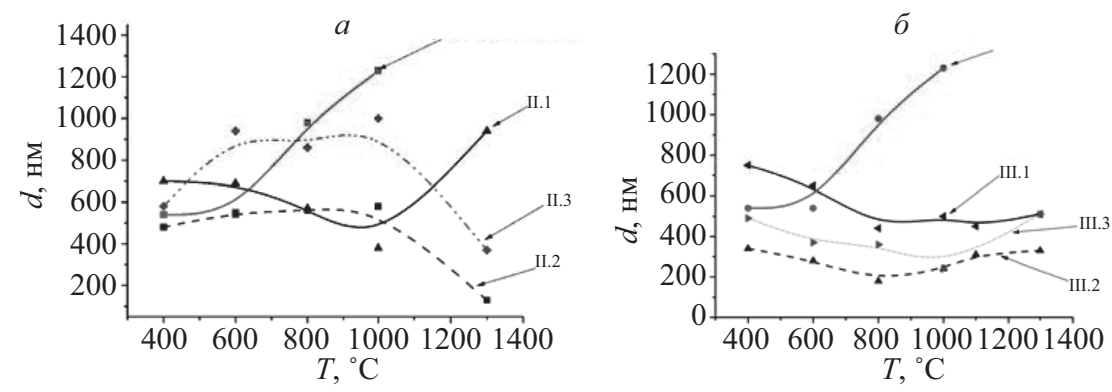

Puc. 6. Зависимость среднего размера агломератов от температуры прокаливания для прекурсоров II $(a)$ и III (б) после криохимической обработки: верхняя стрелочка $-8 \mathrm{Y}_{2} \mathrm{O}_{3}-25 \mathrm{TiO}_{2}-67 \mathrm{ZrO}_{2}$, сушка под давлением

$\left.25 \mathrm{TiO}_{2}-\mathrm{ZrO}_{2}\right)$ наблюдается деагломерация, связанная с удалением структурно связанной воды. Указанные процессы сопровождаются медленным ростом кристаллитов. Выше $520^{\circ} \mathrm{C}$ наблюдаются процессы рекристаллизации, вызывающие незначительный рост агломератов. Дальнейший рост температуры $\left(\geqslant 600^{\circ} \mathrm{C}\right)$ ведёт к их спеканию, сопровождаемому резким ростом размера кристаллитов [22]. На графике видно, что при $1000^{\circ} \mathrm{C}$ средний размер агломератов составляет уже 1230 нм. Кривые зависимости среднего размера агломератов от температуры для прекурсоров после лиофильной сушки в различных вариантах (с добавкой глицерина и без), а также после криохимической обработки в жидком азоте повторяют общий ход описанной выше зависимости. Однако в случае применения криохимической обработки участок, отвечающий деагломерации и рекристаллизации, простирается вплоть до $1000^{\circ} \mathrm{C}$, а участок, отвечающий спеканию, имеет намного меньшую крутизну. Лиофильная сушка способствует получению низкоагломерированного порошка с трёхмерной пористой структурой, повторяющей структуру исходного прекурсора. За счёт того, что удаление дисперсионной среды происходит напрямую из твёрдой фазы в газ, контакт между соседними частицами значительно уменьшается. Таким образом, слипание частиц дисперсной фазы в крупные агломераты удаётся свести к минимуму. Разрушение пористого каркаса связано с началом дегидратации и последующей замедленной кристаллизацией, которая начинается уже при $360^{\circ} \mathrm{C}$ [7]. Формирование флюоритоподобного твёрдого раствора и процессы рекристаллизации происходят вплоть до $800^{\circ} \mathrm{C}$. В составе II описанные конкурирующие процессы фазообразования происходят одновременно с медленным ростом кристаллитов и рекристаллизацией, что подтверждается низкими значениями кристалличности полученных прекурсоров после прокаливания при $400^{\circ} \mathrm{C}$ (см. табл. 4). Деагломерация происходит вследствие рекристаллизации, которая опережает рост кристаллитов в интервале температур до $1000^{\circ} \mathrm{C}$.

При дальнейшем повышении температуры в составе III и прекурсоре II.1 наблюдается спекание агломератов, сопровождающееся медленным ростом кристаллитов. Для сравнения, по данным [19, 20], средний размер агломератов в прекурсорах, полученных золь-гель синтезом с последующей высокотемпературной сушкой под избыточным давлением, после термообработки при $1300^{\circ} \mathrm{C}$ составил $\approx 3 \div 4$ мкм, что почти на порядок выше полученных нами результатов. Резкая деагломерация, имеющая место для прекурсоров II.2 и II.3 в интервале $1000-1300^{\circ} \mathrm{C}$, по всей видимости, связана с окончанием конкурирующих процессов и кристаллизацией равновесных при этой температуре фаз. Добавка глицерина к гелю при лиофильной сушке (кривые II.3 и III.3) способствует 
значительному уменьшению среднего размера агломератов во всём интервале температур. Добавка криопротектора к исходному гелю изменяет поведение воды при замерзании, а именно, при кристаллизации в структуре льда образуются локальные аморфные участки и в процессе замерзания рост больших гексагональных кристаллов оказывается ограниченным. Молекулы глицерина также препятствуют выталкиванию частиц дисперсной фазы из формирующихся кристаллов дисперсионной среды. Таким образом, заморозка сопровождается ростом большого количества мелких кристаллов льда. Прокаливание полученных агломератов ведёт к дегидратации сначала на поверхности, а потом во всём объёме образца.

На основании полученных данных CTA, PФА и PSD-анализа можно сделать следующие выводы о закономерностях фазообразования, а также об эволюции агломератов и кристаллитов в прекурсорах после криохимической обработки, при их последовательной термообработке в области $400-1300^{\circ} \mathrm{C}:$ в области $\leqslant 800^{\circ} \mathrm{C}$ процессы дегидратации, кристаллизации и рекристаллизации происходят одновременно, что приводит к расширению области деагломерации. Для всех исследованных составов кристаллизация происходит согласно правилу ступеней Оствальда и сопровождается формированием метастабильного флюоритоподобного твёрдого раствора на основе диоксида циркония; в области $800-1000^{\circ} \mathrm{C}$ продолжающаяся деагломерация порошков обусловлена удалением остатков структурно-связанной воды и одновременной рекристаллизацией. В составе III происходит окончательное формирование флюоритоподобного твёрдого раствоpa, а в II наблюдается появление примесей низкосимметричных фаз $\mathrm{ZrO}_{2}$; в области $1000-1300^{\circ} \mathrm{C}$ спекание полученных агломератов происходит одновременно с медленным ростом кристаллитов, сопровождающимся образованием равновесного состава, соответствующего данным фазовой диаграммы $\mathrm{CaO}-\mathrm{ZrO}_{2}$.

Заключение. Методами ДСК, РФА, и PSD-анализа проведено комплексное исследование взаимосвязи дисперсности прекурсоров после криохимической обработки и фазовых соотношений в образцах с изменением температуры; выявлены и изучены процессы, ответственные за превращение метастабильных фаз в равновесный твёрдый раствор. Показано, что применение криохимической обработки позволяет элиминировать процессы агломерации прекурсоров до $1000^{\circ} \mathrm{C}$, что способствует стабилизации флюоритоподобного твёрдого раствора на основе диоксида циркония в области температур и концентраций, более широкой, чем на равновесной фазовой диаграмме. Предложен критерий определения полноты кристаллизации метастабильных флюоритоподобных твёрдых растворов в системе $\mathrm{CaO}-\mathrm{ZrO}_{2}$ на основе величины энтальпии кристаллизации при фазовом переходе аморфный прекурсор $\rightarrow$ кристаллический твёрдый раствор.

\section{Литература} 998 с.

1. Иванов-Шиц, А. К., Мурин И. В. Ионика твёрдого тела: в 2 т. СПб.: Изд-во СПбГУ, 2010. Т. 2.

2. Иванов-Павлов Д. А., Конаков В. Г., Голубев С. Н., Ануфриков Ю. А. Исследование взаимосвязи фазового состава керамик $\mathrm{Y}_{2} \mathrm{O}_{3}-\mathrm{TiO}_{2}-\mathrm{ZrO}_{2}$ и их электрохимических свойств // Вестн. С.-Петерб. ун-та. Сер. 4. Физика. Химия. 2010. Вып. 1. С. 39-45.

3. Stevens R. Zirconia and zirconia ceramics. Magnesium Elektron Ltd., 1986.

4. Politova T. I., Irvin J. T.S. Investigation of scandia-yttria-zirconia system as a electrolyte material for intermediate fuel cells - influence of yttria content in system $\left(\mathrm{Y}_{2} \mathrm{O}_{3}\right)_{x}\left(\mathrm{Sc}_{2} \mathrm{O}_{3}\right)_{11-x}\left(\mathrm{ZrO}_{2}\right)_{89} / /$ Solid State Ionics. 2004. Vol. 168. P. 153-165.

5. Nair J., Nair P., Van Ommen J. G., Ross J. R. H., Burggraaf A. J. Effect of post-precipitation treatment on the pore-structure stability of sol-gel-derived lanthanum zirconate // J. Am. Ceram. Soc. 1998. Vol. 81, N 6. P. 1487-1492. 
6. Konakov V. G., Seal S., SolovievaE. N., Golubev S. N., Pivovarov M. M., Shorochov A. V. Influence of precursor dispersity and agglomeration on mechanical characteristics of $92 \mathrm{ZrO}_{2}-8 \mathrm{Y}_{2} \mathrm{O}_{3}$ ceramics $/ /$ Rev. Adv. Mater. Sci. 2006. Vol. 13, N 1. P. 71-76.

7. Kurapova O. Yu., Konakov V.G., Golubev S. N., Ushakov V.M., ArchakovI. Yu. Cryochemical methods for manufacturing nanosized ceramics and ceramic precursor powders with low agglomeration degree: a review // Rev. Adv. Sci. 2012. N 32. P. 14-34.

8. Третъяков Ю. Д., Метлин Ю. Д. Химия силикатов и оксидов. Л.: Наука, 1982. 225 с.

9. Tsipis E. V., Kharton $V$. V. Electrode materials and reaction mechanisms in solid oxide fuel cells: a brief review // J. Solid State Electrochem. 2008. N 12. P. 1367-1391.

10. Konakov V. G., Kurapova O. Yu. Phase evolution in zirconia based ceramics // Rev. Adv. Sci. 2014. N 36. P. 177-190.

11. Deville $S$. Freeze-casting of porous ceramics: a review of current achievements and issues // Adv. Eng. Math. 2008. Vol. 10, N 3. P. 155-169.

12. Stubican V. S., Ray S. P. Phase equilibrium and ordering in the system $\mathrm{ZrO}_{2}-\mathrm{CaO} / /$ J. Amer. Ceram. Soc. 1977. Vol. 60, N 11-12. P. 535-537.

13. Конаков В. Г., Голубев С. Н., Курапова О. Ю., Борисова Н. В., Уиаков В. М. Предыстория получения наноразмерных прекурсоров на основе твёрдых растворов диоксида циркония и их термическая эволюция // Вестн. С.-Петерб. ун-та. Сер. 4. Физика. Химия. 2012. Вып. 2. С. 65-76.

14. Конаков В. Г., Голубев С. Н., Курапова О. Ю., Уиаков В. М. Термическая эволюция, фазообразование и дисперсность наноразмерных прекурсоров на основе стабилизированного диоксида циркония, полученных лиофильной сушкой с добавками криопротекторов // Вестн. С.-Петерб. ун-та. Сер. 4. Физика. Химия. 2013. Вып. 3. С. 72-84.

15. Ivanova E. A., Konakov V. G., SolovyevaE. N. The synthesis of nano-sized powders in the $\mathrm{ZrO}_{2}-$ $\mathrm{HfO}_{2}-\mathrm{Y}_{2} \mathrm{O}_{3}$ system // Rev. Adv. Mater. Sci. 2003. Vol. 3. P. 41-47.

16. Некрасов Б. В. Основы общей химии. М.: Химия, 1969. Т. 2. 399 с.

17. Barin L., Knacke O. Thermochemical properties of inorganic substances. [W. p.]: Springer, 1973. $921 \mathrm{p}$.

18. Синицкий А. С., Кецко В. А., Пентин И. В. и др. Дегидратация гидрофильных оксидов $\mathrm{ZrO}_{2}$ и $\mathrm{Al}_{2} \mathrm{O}_{3}$ при высоких температурах // Журн. неорган. химии. 2001. Т. 48, вып. 3. С. 484-488.

19. Иванова E. A., Конаков В. Г. Проблемы агломерации порошков-прекурсоров системы $\mathrm{ZrO}_{2}-$ $\mathrm{HfO}_{2}-\mathrm{Y}_{2} \mathrm{O}_{3} / /$ Вестн. С.-Петерб. ун-та. Сер. 4. Физика. Химия. 2007. Вып. 2. С. $106-110$.

20. Борисова Н. В., Шорохов А. В, Голубев С. Н., Иванов-Павлов Д. А., Конаков В. Г., Соловъёва E. Н., Ушаков В. М. Эволюция гелей на основе систем $\mathrm{Y}_{2} \mathrm{O}_{3}-\mathrm{ZrO}_{2}, \mathrm{Ce}_{2} \mathrm{O}_{3}-\mathrm{ZrO}_{2}$ и $\mathrm{Ce}_{2} \mathrm{O}_{3}-\mathrm{Y}_{2} \mathrm{O}_{3}-$ $\mathrm{ZrO}_{2}$ при их последовательной термической обработке // Вестн. С.-Петерб. ун-та. Сер. 4 . Физика. Химия. 2008. Вып. 3. С. 64-70.

21. Линсен Б. Г. Строение и свойства адсорбентов и катализаторов. М.: Мир, 1973.648 с.

22. Конаков В. Г., Курапова О. Ю., Борисова Н. В., Голубев С. Н., Соловъёва Е. Н., Уиаков В. М. Зависимость физико-химических свойств и размеров прекурсоров оксидной керамики на основе твёрдых растворов диоксида циркония от способа синтеза // Вестн. С.-Петерб. ун-та. Сер. 4. Физика. Химия. 2011. Вып. 3. С. 48-59.

\section{References}

1. Ivanov-Shiets A. K., Murin I. V. Ionica tverdogo tela [Ionics of a solid body]. St. Petersburg, SPbGU Publ., 2010, vol. 2. 998 p. (In Russian)

2. Ivanov-Pavlov D. A., Konakov V. G., Golubev S. N., Anufrikov Yu. A. Issledovanie vzaimosvjazi fazovogo sostava keramik $\mathrm{Y}_{2} \mathrm{O}_{3}-\mathrm{TiO}_{2}-\mathrm{ZrO}_{2}$ i ih jelektrohimicheskih svojstv [Investigation of interrelation between phase composition and electrochemical characteristics in the $\mathrm{Y}_{2} \mathrm{O}_{3}-\mathrm{TiO}_{2}-\mathrm{ZrO}_{2}$ system]. Vestnik St. Petersburg University. Series 4. Physics. Chemistry, 2010, iss. 1, pp. 39-45. (In Russian)

3. Stevens R. Zirconia and zirconia ceramics. Magnesium Elektron Ltd., 1986.

4. Politova T. I., Irvin J. T. S. Investigation of scandia-yttria-zirconia system as a electrolyte material for intermediate fuel cells — influence of yttria content in system $\left(\mathrm{Y}_{2} \mathrm{O}_{3}\right)_{x}\left(\mathrm{Sc}_{2} \mathrm{O}_{3}\right)_{11-x}\left(\mathrm{ZrO}_{2}\right)_{89}$. Solid State Ionics, 2004, vol. 168, pp. 153-165.

5. Nair J., Nair P., Van Ommen J. G., Ross J. R. H., Burggraaf A. J. Effect of post-precipitation treatment on the pore-structure stability of sol-gel-derived lanthanum zirconate. J. Am. Ceram. Soc., 1998, vol. 81, no 6, pp. 1487-1492.

6. Konakov V. G., Seal S., Solovieva E. N., Golubev S. N., Pivovarov M. M., Shorochov A. V. Influence of precursor dispersity and agglomeration on mechanical characteristics of $92 \mathrm{ZrO}_{2}-8 \mathrm{Y}_{2} \mathrm{O}_{3}$ ceramics. Rev . Adv. Mater. Sci., 2006, vol. 13, no 1, pp. 71-76. 
7. Kurapova O. Yu., Konakov V. G., Golubev S. N., Ushakov V. M., Archakov I. Yu. Cryochemical methods for manufacturing nanosized ceramics and ceramic precursor powders with low agglomeration degree: a review. Rev. Adv. Sci., 2012, no 32, pp. 14-34.

8. Tretyakov Yu. D., Metlin Yu. D. Khimia silikatov i oksidov [Chemistry of silicates and oxides]. Leningrad, Nauka Publ., 1982. 225 p. (In Russian)

9. Tsipis E. V., Kharton V. V. Electrode materials and reaction mechanisms in solid oxide fuel cells: a brief review. J. Solid State Electrochem., 2008, no 12, pp. 1367-1391.

10. Konakov V. G., Kurapova O. Yu. Phase evolution in zirconia based ceramics. Rev. Adv. Sci., 2014, no 36 , pp. $177-190$.

11. Deville S. Freeze-casting of porous ceramics: a review of current achievements and issues. Adv. Eng. Math., 2008, vol. 10, no 3, pp. 155-169.

12. Stubican V.S., Ray S. P. Phase equilibrium and ordering in the system $\mathrm{ZrO}_{2}-\mathrm{CaO}$. J. Amer. Ceram. Soc., 1977, vol. 60, no 11-12, pp. 535-537.

13. Konakov V. G., Golubev S. N., Kurapova O. Yu., Borisova N. V., Ushakov V. M. Predystorija poluchenija nanorazmernyh prekursorov na osnove tvjordyh rastvorov dioksida cirkonija i ih termicheskaja jevoljucija [Investigation of prehistory of precursors for obtaining stabilized cubic zirconia based nanopowders and their thermal evolution]. Vestnik St. Petersburg University. Series 4. Physics. Chemistry, 2012, iss. 2, pp. 65-76. (In Russian)

14. Konakov V. G., Kurapova O. Yu., Golubev S. N., Solovieva E. N., Ushakov V. M. Termicheskaja jevoljucija, fazoobrazovanie i dispersnost' nanorazmernyh prekursorov na osnove stabilizirovannogo dioksida cirkonija, poluchennyh liofil'noj sushkoj s dobavkami krioprotektorov [The effect of the cryoprotectant on thermal evolution, phase formation and dispersity of freeze-dried stabilized zirconia nanosized powders]. Vestnik St. Petersburg University. Series 4. Physics. Chemistry, 2013, iss. 3, pp. 72-84. (In Russian)

15. Ivanova E. A., Konakov V. G., Solovyeva E. N. The synthesis of nano-sized powders in the $\mathrm{ZrO}_{2}-$ $\mathrm{HfO}_{2}-\mathrm{Y}_{2} \mathrm{O}_{3}$ system. Rev. Adv. Mater. Sci., 2003, vol. 3, pp. 41-47.

16. Nekrasov B. V. Osnovi obschei khimii [Fundamentals of the general chemistry]. Moscow, Khimiia Publ., 1969, vol. 2. 399 p. (In Russian)

17. Barin L., Knacke O. Thermochemical properties of inorganic substances. [W. p.]: Springer, 1973. $921 \mathrm{p}$.

18. Sinitsty A. S., Ketsko V. A., Pentin I. V. et al. Degidratatsiia gidrofil'nykh oksidov $\mathrm{ZrO}_{2}$ i $\mathrm{Al}_{2} \mathrm{O}_{3} \mathrm{pri}$ vysokikh temperaturakh $\left[\mathrm{ZrO}_{2}\right.$ and $\mathrm{Al}_{2} \mathrm{O}_{3}$ hydrophilic oxides dehydration at high temperatures]. Zhurn. neorgan. khimii. [Rus. J. Inorgan. Chem.], 2001, vol. 48, iss. 3, pp. 484-488. (In Russian)

19. Ivanova E. A., Konakov V. G. Problemy aglomeracii poroshkov-prekursorov sistemy $\mathrm{ZrO}_{2}-\mathrm{HfO}_{2}-$ $\mathrm{Y}_{2} \mathrm{O}_{3}$ [Problems of agglomeration of powders precursors of system $\mathrm{ZrO}_{2}-\mathrm{HfO}_{2}-\mathrm{Y}_{2} \mathrm{O}_{3}$ ]. Vestnik St. Petersburg University. Series 4. Physics. Chemistry, 2007, iss. 2, pp. 106-110. (In Russian)

20. Borisova N. V., Shorohov A. V., Golubev S. N., Ivanov-Pavlov D. A., Konakov V. G., Solovieva E. N., Ushakov V. M. Jevoljucija gelej na osnove sistem $\mathrm{Y}_{2} \mathrm{O}_{3}-\mathrm{ZrO}_{2}, \mathrm{Ce}_{2} \mathrm{O}_{3}-\mathrm{ZrO}_{2}$ i $\mathrm{Ce}_{2} \mathrm{O}_{3}-\mathrm{Y}_{2} \mathrm{O}_{3}-\mathrm{ZrO}_{2}$ pri ih posledovatel'noj termicheskoj obrabotke [Evolution of gels in the $\mathrm{Y}_{2} \mathrm{O}_{3}-\mathrm{ZrO}_{2}, \mathrm{Ce}_{2} \mathrm{O}_{3}-\mathrm{ZrO}_{2}, \mathrm{Ce}_{2} \mathrm{O}_{3}-$ $\mathrm{Y}_{2} \mathrm{O}_{3}-\mathrm{ZrO}_{2}$ systems under step by step treatment]. Vestnik St. Petersburg University. Series 4. Physics. Chemistry, 2008, iss. 3, pp. 64-70. (In Russian)

21. Linsen B. G. Stroenie i svoistva adsorbentov i katalizatorov [The structure and properties of adsorbents and catalysts]. Moscow, Mir Publ., 1973. 648 p. (In Russian)

22. Konakov V. G., Kurapova O. Yu., Borisova N. V., Golubev S. N., Solovieva E. N., Ushakov V. M. Zavisimost' fiziko-himicheskih svojstv i razmerov prekursorov oksidnoj keramiki na osnove tvjordyh rastvorov dioksida cirkonija ot sposoba sinteza [The effect of a sintering method on the precursor powder size and physical-chemical properties of final cubic zirconia ceramics]. Vestnik St. Petersburg University. Series 4. Physics. Chemistry, 2011, iss. 3, pp. 48-59. (In Russian)

Статья поступила в редакцию 12 апреля 2016 г.

Кон тактн ая ин формация

Курапова Олъга Юръевна - кандидат химических наук; e-mail: olga.yu.kurapova@gmail.com Конаков Владимир Геннадиевич - доктор химических наук, профессор; e-mail: glasscer@yandex.ru Голубев Сергей Николаевич - кандидат химических наук; e-mail: glasscer@yandex.ru

Ушаков Виктор Михайлович - кандидат химических наук; e-mail: glasscer@yandex.ru

Kurapova Olga Yurievna — PhD; e-mail: olga.yu.kurapova@gmail.com

Konakov Vladimir Gennadievich — Doctor of Chemistry, Professor; e-mail: glasscer@yandex.ru

Golubev Sergey Nikolaevich — PhD; e-mail: glasscer@yandex.ru

Ushakov Victor Mikhailovich — PhD; e-mail: glasscer@yandex.ru 